\title{
Can harmonized regulation overcome intra-European differences? Insights from a European Phase III stem cell trial
}

\author{
Christine Hauskeller*,1 \\ ${ }^{1}$ Department of Sociology, Philosophy \& Anthropology, University of Exeter, Byrne House, St Germans Road, Exeter EX4 4PJ, UK \\ * Author for correspondence: c.hauskeller@exeter.ac.uk
}

\begin{abstract}
Harmonized regulation of research with human stem cells in Europe has shaped innovation in regenerative medicine. Findings from a Phase III academic clinical trial of an autologous cell procedure illustrate the obstacles that a multinational trial faces. A typology of the obstacles encountered, may help other teams embarking upon trials. The findings throw light on the situation of clinician-scientists in clinical innovation, as the expertise to run scientific trials is very complex. The innovation route of clinical translation takes insufficient account of the interdependencies between multiple social and cultural factors from outside the laboratory and the clinic. For ethical reasons, however, academic and business routes to stem cell treatments ought to be enabled by the regulators. Suggestions arise, how academics can prepare for trials, that academic research needs better institutional support and that new models of medical innovation may need to be developed for regenerative medicine.
\end{abstract}

First draft submitted: 26 April 2017; Accepted for publication: 27 July 2017; Published online: 4 October 2017

Keywords: ATMP • autologous stem cell treatments $\bullet$ ethics $\bullet$ international harmonization $\bullet$ medical procedures $\bullet$ medicine as science $\bullet$ Phase III clinical trial $\bullet$ regulation $\bullet$ standards

The landscape of regulations applying to innovations and medicine, and especially with human cells and tissues is chequered and shapes the socio-political environments in which regenerative medicine (RM) proceeds. Europe has very strict governance regimes in place that not only prevents rogue marketing of cell treatments, but also adds a high logistical and cost burden to the development of future therapies. Progress in approved clinical treatments is slow and pathways toward them are sought that solve the conundrum of pressing consumer demand and patient need, the problems arising from existing forms of regulatory oversight and the long time and high financial stakes involved in bringing new treatments into the clinic via the staggered model of the scientific clinical trial (CT). Medical translation from the laboratory bench to the bedside has become increasingly fraught with problems while it has become imperative for science to demonstrate its applicability [1-3].

Salter, Zhou and Datta [4,5] discuss four innovation models for stem cell (SC) therapies. Model I is called "Scientific SC Innovation." This model follows the multistep process from basic research to clinical application in the established well-defined stages of the CT. They then discuss three other models (II, III and IV) that bridge the gulf between the traditional CT and patient-based or exemption-based uses of new treatments. Models II-IV make use of different ways of collecting data about the effects of experimental treatments, processes of scaling up from a physician or hospital exemption that are not formal CTs and tensions between the professional ethos of medicine and the technical approach to standardize that characterizes most regulations. For these models, they use the umbrella term "Medical SC Innovation." Models II, III and IV follow a wider set of prerogatives than the scientific model. They are often build on patients' self-reported health improvements and respond to the individual patient's needs or to the patient-consumers, who apply - and often pay - to receive SC treatments that are not scientifically validated as required by Model I. Salter and colleagues distinguish the western type of medical innovation, using the hospital exemption specified in the European regulations (Model II), from two non-western types (Models III and IV) and highlight and problematize what they see as a paradox, namely that: 
"the vast majority of the stem cell therapy market activity is in the domain of medical innovation (Models II, III and IV), the vast majority of official policy discourse and public commentary focuses on the domain of scientific innovation (Model I). The regulatory debate has largely focused on the scientific innovation stages of clinical experimentation and clinical trials of Model I, stages that are absent from the medical innovation models." (4, p. 358).

The notion of Medical SC Innovation adds regulatory and industrial actors to the scene described in translational medicine and considers patients as influential stakeholders. It highlights the close interdependency of science and medicine with social values and practices, especially technological and economic infrastructures in which a political economy of commercial value creation and consumer demand plays a role.

In order to manage conflicting interests and the rapid developments in the field, SC RM has become firmly regulated and existing regulations have been harmonized in Europe with Directives on CTs conduct and with the use of cells and tissues as well as advanced medicinal therapy products (ATMP) regulation. Among the conflicting interests are included various ethical value orders, not least concerning the use of human embryos and tissues, as well as the varied organization of medical service provisions on the scale from private to public dependent upon the rules of partner countries. A second aspect concerning the harmonizing of regulations is the scientific need to draw upon large populations to recruit qualifying patients from different backgrounds to CTs in order to demonstrate the efficacy of new interventions. The protection of vulnerable patients and moral values, as well as the wish to safeguard speedy yet reliable scientific progress for treatments, do not integrate harmoniously into a regulatory and research pathway. All the more so when a third aspect must be considered, namely the wish to create sound revenue streams from a future RM. This last aspect illustrates another set of conflicting interests. The pharmaceutical industry sees itself as integral to the development of future cell therapy treatments and is bound by tight regulations - yet hundreds of private companies and hospitals, exploiting regulatory loopholes or in countries where no strict regulation is in place, offer SC injections on a direct to consumer basis to patients who often travel far to buy them. Scandals arising from patient deaths play a major role in calls for tighter regulations such as those developed in Europe in the late 2000s. Private hospitals' business models from companies such as the now closed XCell Center in Germany [6] are mobile and hundreds of thousands of patients have bought such treatments, especially in Asia and in certain states in the USA [7-10]. The inevitable limitation of national or, in the case of Europe, transnational laws and regulations has been discussed widely in the literature on life science governance and SC research $[11,12]$. International professional associations occasionally take on the role of setting global standards, in this case the International Society for SC Research (ISSCR), which issued and re-issued guidelines for translation in 2008 and 2016 [13,14]. But those guidelines are not compulsory and appeal only to those bound by professional ethics. Exemptions that are part of the patient-doctor relationship to try new treatments if everything else has failed are a regular part of all compulsory regulations currently in place and conflated with the offers of unproven SC treatments in the open market. Many call for ways of overcoming the conflicting interests tied to the unsatisfactory present regulatory situation in order to advance RM and control a mushrooming industry that puts at risk patient lives and the reputation of the field of RM. But, similar to other direct-to-consumer markets in biomedicine, the lack of global reach of legal or regulatory interventions to govern emerging consumer markets seems to leave three other options: one are professional standards often issued by transnational bodies such as the ISSCR mentioned above, another are quality certificates similar to ISO standards for product [15], a third is public engagement to educate publics about the risks and costs of unproven SC treatments [16]. This article presents details on how the current European regulations.

This article presents findings from a sociological study alongside an ongoing multinational European Phase III SC CT. The findings illustrate how difficult translation can be and that the common focus on knowledge transfer and application in translational medicine underestimates the impact of regulation and cultural diversity on the process of clinical innovation. On the basis of the findings from this study, I discuss how the tight regulations in Europe for RM CTs shape the field of research and the clinical introduction of new treatments. The findings give grounds to enquire as to whether or not the current design of regulation in Europe actively prevents the introduction of certain RM treatments into the clinic instead of making SC therapies safe, stifling the advance of a tried and tested autologous SC procedure at the late CT stage. At present, mass produced off-the-shelf cell therapies are not well advanced, with three quarters of SC trials using autologous cells. Autologous treatments can be similar to medical procedures, as in the reported case study. They do not offer the option of intellectual property rights, they are local and they cannot be scaled up. 
It seems crucial for the realization of the ideas and technologies available to the field of RM that regulation fosters the clinical development and use of cell-based therapies that are safe, efficacious and affordable for patients and healthcare systems. This article aims to advance the discussion on how translation of SC therapies into the clinic can proceed by contributing a better understanding of the implications and effects of the relatively stringent regulations which the European Union has brought into force. The case study is a fully approved, regulation compliant randomized, controlled Phase III trial in autologous SC medicine in Europe, the field in which both clinically validated and unproven treatments are most frequent at present $[11,16]$.

\section{Methods \& case study}

Social scientific studies have accompanied SC research from its inception in the late 1990s to the present [17]. Human embryonic SCs attracted critical debate among experts and the public, largely because of the contested use of human embryos for the derivation of human embryonic SC lines [18,19]. The potential for a new form of therapy led to changes in national laws or to exemptions from prohibitions on embryo research [20,21]. By contrast, bone-marrow-derived SCs had been used clinically for decades [22]. When the cultivation of embryo-derived cells created the prospect of a large field of RM, many different types of adult SCs from living donors were explored by scientists and clinicians as alternative approaches to developing cell-based RM.

The sociological research reported records and analyses the effects of European harmonization policies on the trial entitled "The effect of intracoronary reinfusion of bone-marrow-derived mononuclear cells on all-cause mortality in acute myocardial infarction (AMI), " or BAMI in short. BAMI is a clinician-led (academic), randomized, controlled CT - strictly following what Salter and colleagues characterize as the western ideal pathway of scientific innovation in medicine, Model I [4,5]. BAMI is a Phase III trial largely funded by a research grant from the European commission. A bone-marrow-derived SC filtrate is used in autologous application to treat the patient. The history of this particular application of autologous bone-marrow has been trialed since the early 2000s. In reviews, Phase I and II trials have shown ambiguous results [23,24]. The scientific aim of the trial is to establish whether mortality after severe AMI decreases following with this SC procedure [25]. As one of the principle investigators (PI) on the BAMI grant and project, I have been and I will be, observing BAMI from the preparation of the funding application in 2009 to trial completion - expected for 2019. The research objective of my work package in BAMI is to trace the trial's implementation process and conduct, including collecting views of those who conduct BAMI, on trial conduct.

The sociological methods used in my accompanying study include participant observation, interviews with and mini-surveys or questionnaires answered by, team members across the functions in the trial. The findings reported here are based on several different data collections including two mini questionnaires and 28 interviews (between 30 and $90 \mathrm{~min}$, some face-to-face, others via Skype). The first mini-questionnaire was introduced at the BAMI 'Kick-off Meeting' in London in 2011 and answered by 14 partners from eight partner countries. In 2014, 28 semi-structured interviews were conducted with 25 clinical members (PIs, National Coordinating Centre [NCC] staff, cardiologists, study nurses) and three managers of trial-wide infrastructure, because some technical and administrative roles had been organized centrally, the echocardiography interpretation (decisive for patient inclusion), patient randomization, as well as the administrative tasks of the sponsor, Queen Mary University of London, which hosts the central trial office. Queen Mary University and the BAMI trial office shoulder the responsibility for major steps such as recruitment site initiation, monitoring, maintaining databases and keeping the overall trial up and running as well as maintaining sponsor links and dealing with governance issues relating to regulatory authorities and the financial administration, which includes tasks such as insuring the trial. The interview data were collected at the different national clinical coordination sites when they had started patient recruitment. Interviews were audio-recorded and transcribed. The interview questions centered on findings from the participant observation of regulatory approval processes and pilot interviews. Finally, responses to and validation of the interpretation of the findings was sought in a 'finding check' mini-questionnaire at a partner meeting in February 2015. The questionnaire used was also forwarded to team members and study nurses absent from the meeting. A total of 22 respondents from nine countries provided their views on the identified findings and their relative impact on the implementation and running of the trial. In July 2016, BAMI has been recruiting patients in Belgium, the Czech Republic, Denmark, Finland, Germany, Italy, the Netherlands, Spain and the UK.

The following summative presentation of issues faced in BAMI is organized into four themes: Regulatory Approval, Regulatory Standards and National Differences, Cultural Issues and Scientific Innovation in Academic Medicine - Time and Money. I close with a future perspective on how these issues might be addressed to advance 
not only industrial but also academic SC therapy innovation in Europe. Detailed accounts of the empirical findings with direct quotations and extended sociological discussions have been published [26,27]. This concise presentation with regard to the debate on RM regulation highlights problems that especially affect academic research teams and research on SC medical procedures. It may provide a useful roadmap for other groups preparing future RM CTs.

\section{Findings}

\section{Regulatory approval}

EMA \& voluntary harmonization procedure

Initially, regulatory approvals by the EMA and National Competent Authorities (NCA) using the new voluntary harmonization procedure (VHP) were not a big hurdle. Following a discussion of the demands from ethics committees and NCAs, the BAMI PIs worked through issues encountered previously to develop a suitable protocol. This meant refining the trial-wide standardization of patient inclusion and exclusion criteria and organizing joint practice as well as streamlining informed consent and ethical approval procedures. With this accomplished, initial EMA and VHP approvals were obtained roughly within the time frame envisaged (1 year). However, when technical and recruitment problems compounded later in the implementation process thereby making requisite changes to the trial protocol, approval renewal procedures began to add to delays - this is an aspect to which I will return below.

Practically problematic was fulfilling the requirements set by regulation. The streamlined implementation rules of the EU Tissue and Cells Directive (EUTCD) came into effect between the planning and starting of the trial. In 2010, the new European Committee for Advanced Therapy classified the cell product used in BAMI as requiring compliance with ATMP laboratory processing rules as defined in the relevant EU Directives. When the EMA and VHP applications were prepared in 2011/2012, cell preparation and delivery methods had to be standardized in all technical aspects across BAMI to comply with Advanced Therapy and Investigative Medicinal Product (ATIMP) regulation.

Bone-marrow derived cell applications have a long history of collection, processing and transplantation. Hematology laboratories that processed bone-marrow SCs (BMSC) for the use in AMI CTs Phase I and II are available in major research hospitals. The PIs had conducted such trials locally, using their local hematology laboratory for cell preparation. The BAMI trial had been planned and costed accordingly. Fulfilling this much higher and very specific protocol for cell processing required access to other laboratories that were qualified not just to sort the cells according to size but to turn the patients' BMSC into something like a standardized medicinal product, even though it would only be used for the cell donor him- or her-self.

\section{Advanced Therapy \& Investigative Medicinal Product \& GMP}

Putting these requirements into practice became a major cause of delay of patient recruitment. Previously, it had been assumed that six BAMI partners could offer cell processing centers. When checking these laboratories, only three qualified fully with the licensing and manufacturing standards now in place. Acquiring a license was too laborious and costly and thus it became necessary to transport the cells to the few ATMP laboratories to which BAMI had access (in Germany, Spain and Denmark) and to start negotiating the use of laboratories in closer proximity where possible. The cell processing locations needed their regulator's approval for transporting cells to other countries and travel routes compliant with regulations for IMPs had to be arranged. The transporting of patients' bone-marrow cells to one of the three ATMP laboratories in BAMI is still ongoing and is proving to be both a cost factor and a logistical burden. The staff cost related to ATIMP cell transportation requirements meant that one partner country could not contribute to patient recruitment at all. Moreover, though since 2010 many new fully ATMP compliant laboratories have been opened at European research hospitals, often with funding support from the European Commission, BAMI recruitment sites in Belgium, the Czech Republic, Italy, Finland and the UK still send the cells to one of the three initial cell processing centers. Further still, the CT protocol prescribes a $24 \mathrm{~h}$ maximum time between cell aspiration and cell processing, and again between the end of processing and reinjection into the patient. Any obstacles or delays encountered along the travel routes can render compliance and thus patient inclusion impossible.

\section{Voluntary harmonization procedure \& regulatory regress}

New regulatory rules always come with teething problems [28]. The VHP started in 2010 and has been managed on behalf of the EMA by the Paul-Ehrlich Institute in Langen, Germany. One example from BAMI that illustrates 
that a new regulation and regulator can - in this case briefly - disrupts a trial project. The Paul-Ehrlich Institute had requested in its VHP approval that the bone-marrow cells be stored in tubes free of endotoxins. The German team and the affiliated company, 't2cure', responsible for the acquisition of devices for cell processing, tried the cell selection procedure with endotoxin-free tubes. In every experiment endotoxin-free tubes spoilt the bone-marrow cells for further use. The cells clotted within minutes. Moreover, endotoxin-free tubes are difficult to obtain as there is only one manufacturer of them in Europe. The specific requirements for the tubes used for transporting bone-marrow resulted in lengthy discussions and ultimately an amendment to the BAMI protocol: the technical requirement to use endotoxin-free tubes was dropped.

Important to note here is that preparing a multinational trial requires detailed familiarization with the regulatory procedures likely to be in force when the trial is to start. Securing both access to the cell processing facilities needed and staffing capacity are important as well. Cell transport licenses may be required, which alone took up to 8 months to obtain in some countries after EMA and VHP approval, before trial site initiation could even be considered. The growing number of ATMP/GMP certified laboratories in Europe will help in avoiding such costly and logistically difficult problems in the future for those who have easy access.

\section{Regulatory standards \& national differences}

BAMI PIs knew that the standard clinical practice treatment of acute AMI was the same across Europe. This is, however, not the case for all the devices and drugs that may be used. A specific drug that prevents blood clotting and is used in BAMI had not been approved for use by the national authorities in one of the partner countries. The use of this drug was part of the treatment protocol and the PI in the respective country had to apply for it. The PI did successfully gain an exemption for restricted use of the drug in the BAMI trial from the national authorities. Supply was arranged through another BAMI NCC. Other partners were troubled by the cost of this drug. Solutions were bulk buying and distribution at a reduced price. The logistics and licensing for this arrangement in adherence with the trial protocol required extensive preparation.

Another requirement is that the bone-marrow aspirating and SC reinjecting clinicians must hold a good clinical practice certificate. In some EU countries, those need to be obtained once, in others, such as the UK, they need to be renewed biannually. Since this certification is part of the harmonized procedure and since BAMI has been headed by a hospital in the UK, all staff in BAMI undertaking these tasks needed recent good clinical practice certificates. Despite the BAMI trial office making renewal as easy as possible, completing it was not readily achieved at all sites.

Alignment in all aspects of the trial protocol must be assured. At the start, the clinicians leading BAMI were, unsurprisingly, not fully aware of some of the mundane bureaucratic licensing issues the teams would encounter.

\section{National \& cultural environment issues}

In addition to regulatory approvals of the CT and its protocols and sorting out technical compliance with the standards set, the clinical teams in each country and location also need to have local hospital ethics approval for the trial.

Having EMA and VHP approval in place should ease that process, but during this step another set of issues emerged that affected implementation and cost time; namely a wide spectrum of variations in patient care as well as established ethical best practice across European countries and regions that I will refer to as cultural issues. They relate to the way in which the local healthcare system is organized, how doctor-patient relations are understood and how such environmental issues of attitudes and institutional organization affect informed consent practices. The local ethics application includes approval of the patient information sheet and the informed consent sheet, both usually prepared in the local language. The ethics committee also makes sure that insurance for the trial is adequate in their eyes. These points among others affected one or more BAMI sites.

\section{Patient information sheets}

The English language sheets were translated and adapted to local requirements and submitted to the local clinical ethics committee. It was found that the principles concerning how much and what information patients ought to receive differ widely across European countries. Some felt that the information to potential patients provided in the UK is too detailed and too medical in language to be appropriate. Patient information sheets were adapted to fit local practice. 
Another cultural difference highlighted in our data on consent practices is how the relationship between clinical team and patients is conceived and configured through bureaucratic processes. While this is mostly tacit knowledge and outside the CT protocol, when discussing the content of patient information sheets such differences become indirectly apparent. The UK sheet reassures patients that the trial is insured and requests that if they have any concerns about negative health effects or of not being treated as they ought to be, they should contact the clinical team which would then contact the insurer. In other countries this seems inadequate. The patient must be able to contact the insurer without having to go via the medical team who treated them and who might have caused them harm. In Germany - for example, the patient information sheet has to list a telephone number of the insurer. This must be a national phone number. While the trial is harmonized in all aspects of clinical patient treatment, the variety of cultural conventions makes itself felt in respect to patient information and communication.

The informed consent and patient information sheets from one country cannot just be translated into the language of another as their content will differ. These translations as such often need to be approved by a certified medical translator and their content is a matter of negotiation between the NCC and the ethics committee or committees. This is compounded by the possible need to recruit patients whose familiarity with the local language is not such that the clinical teams are certain they understand the information. This problem arises predominantly at particularly international patient recruitment sites such as Frankfurt, London and Rome. The existence of patient information and informed consent sheets in English or French is not sufficient as the content of these sheets in the countries is not the same, so certified translations of these sheets still need to be provided.

\section{Insurance}

Insurance of the trial turned out to be an issue beyond ensuring that patient interests were protected. The overall trial insurance had to be complemented by additional insurances in some countries. The trial sponsor has to insure the trial, including risks to patients. In some locations, the annual renewal practice for the trial insurance, customary in the UK for all insurance contracts, was deemed insufficient. It was a matter of concern that patients would each be in the trial for over 2 years and thus that renewal might become difficult should any incidents occur. Additional patient insurance had to be bought in these countries (e.g., in Germany, Italy and Spain). Many NCCs required the BAMI insurance policy to be translated into their own language so that it could be checked by the ethics committees. This too came at a cost; financially and in staff time. For the sponsor as well as for the clinical teams running the NCCs it has been tricky to discover what exactly needs to be done for each locality and to whom one should speak. While each NCC is familiar with how the process works in their country, finding out enough detail to put insurance in place so that every partner's needs were satisfied was an effort.

The lesson from this is that an unexpected amount of very detailed and locality-specific knowledge is required that is not readily available in places of academic research. What exactly has to be insured and the ways in which patients ought to be informed differ across the BAMI partner countries according to local cultural conventions and ethical perceptions. Having acquired much of this expertise through a trial and error approach has advanced the knowledge of the BAMI NCC staff enormously. But many NCC staff remarked on the huge difference in experience and effort between running an industry sponsored trial, where all these cultural issues are taken care of by the funder and this academic trial. For readers interested in how our interviewees described these cultural problems, more detail on these findings has been published [27].

\section{Scientific innovation in academic medicine: money, time \& staff retention}

Dealing with the issues listed above adds staff effort and staff time. Unsurprisingly, academic researchers and their host institutions, which traditionally operate at the local level, do not have the experience and in-house knowledge to quickly solve problems such as multinational insurance cover or language translation. Far more funding could have eased many of the obstacles the BAMI team faced and overcame in order to comply with harmonized regulations. But more money alone would have been of limited use for addressing the cultural issues, though sufficient staff and staff continuity would certainly help here as well. Adding a professional Clinical Research Organization (CRO) to the group of partners in BAMI might have been an answer. If the degree of difficulties to overcome had been known when the trial was in the planning stages, a engaged CRO might have been given a larger role in BAMI. The convoluted conditions arising from regulatory changes that blew the BAMI budget before the trial even started on the one hand, paired with a lack of awareness of the degree to which limited funding and other cultural practicalities would affect trial conduct midterm, explain why this may not have been duly considered at the time. 
When a project is scheduled to last for 5 years or, all in all 8 years now, finite funding affects commitment and staff continuity. Additionally, many of the participating centers are involved in parallel trials, most of which are industry sponsored. This is partly inevitable and required to recover the costs for running BAMI. At the same time, it means that cheerleading for BAMI across the large team is one of the major tasks of the leading academics and the BAMI trial office. From the point of view of many of the partners though, as very recent observations confirm again, the project appears largely as one as slowed down by obstacles that arise elsewhere and about which individual partners cannot do much. The passion for conducting the research, the clinicians firmly believe in, but which they see side-lined by regulators and industry, occasionally wanes over this long time - keeping it going shows great skill and commitment to the academic research pathway by the participating clinical teams.

Timing is crucial and BAMI was unfortunately between major regulatory changes that demanded a different local infrastructure to conduct the trial. To the availability of fully GMP certified laboratories has increased markedly with strong support from the European Commission. Without easy access to such facilities, research in RM is now neigh impossible.

Time delays and lack of funds affected other parts of the trial in the long-term and required re-approval by the EMA and through VHP. Not only do staff take on new posts over such long periods of time, but also both the standard therapy in the patient control group, as well as the materials and equipment used in the trial, might change. With time these risks rise. If another innovation in AMI patient treatment were to be implemented while the trial is ongoing, the patients treated previously and those treated after that change could not be compared with each other - but it would be ethically impermissible not to treat patients to the best standard of care. This is one of the reasons why Phase III trials are likely to be conducted across many countries. They must try to recruit the high patient numbers for a specialized treatment and a narrowly defined patient group.

Similarly, equipment needs to remain the same throughout under ATMP. That made it seem sensible to purchase from the outset sufficient equipment to treat all patients. Having to buy equipment from a new production batch would require re-approval - scientific validity is deemed at stake. However, every item of clinical and pharmaceutical equipment has a use-by date after which the manufacturer no longer guarantees that it still meets all quality specifications. Sterility and efficacy of solutions in vials and pharmaceuticals used in the cell processing laboratories are the primary concern here. Because of the time delays, BAMI confronted both problems: that batches of equipment ran out of use over the protracted recruitment period. Protocol changes and re-approval by the EMA and NCAs via VHP were necessary. Those added to the overall delay, not least because in some countries NCAs require that patient recruitment must be halted while re-approval is sought, which in some countries can still take many months, even though following VHP it should not.

Time delays in BAMI led to new problems causing additional time delays. The European harmonized regulatory setting and VHP were aimed at speeding up RM innovation. However, once first problems in the flow of work arise, the cumbersome procedures of reapproval and still patchy full compliance with their rules can add to the initial trouble and time delay.

\section{Discussion}

The findings from the experiences in BAMI illustrate how European harmonized regulation affects trial implementation. Laying out these effects should contribute several aspects to the ongoing debate about regulatory regimes for RM, two of them I will highlight. The current European regulatory situation may be a serviceable bulwark against markets for unproven cures but it also hampers academic research consortia who try to develop autologous therapies within the strict framework of the CT paradigm, Model 1 in Salter and colleagues' terminology $[4,5]$. The paradigm itself is thus put into question for therapy pathways such as autologous, which are not industry sponsored. In order for local, affordable SC therapies to become part of a validated clinical treatment regime with reimbursement options, such therapies might need to be developed possibly taking other existing models as an inspiration.

BAMI was intended as a scaling up from Phase I or II trials to a Phase III trial and the range of new challenges this entails was unexpected, especially in the multinational setting. Large numbers of patients and specialized industrial production modalities for the trialled therapeutic are required for scientific validity of the procedure trialed. European regulations have effectively aligned standards of scientific medical research (i.e., generalisability and statistical data on efficacy) with standards of product development, more so with recent regulatory changes to the EUTCD and its ATMP amendment. 
The institution of the clinic is highly integrated with other societal practices. This makes it a difficult space for scientific innovation in the form of the big CT. Structurally, problems of the kind described above are inevitable, the larger and more multi-sited the trial the more so. Taken together, the problems encountered, the difficulties in overcoming them and the human cost in terms of staff time and effort all seem to suggest that academic Phase III trials in Europe are almost impossible without the support of a very experienced and capable CRO. Private companies offer such services at a price.

A group of clinicians, highly experienced with smaller ATMP trials in cardiology, came together for an academic Phase III RMCT to study a SC application that has shown promising results in previous studies and won $€ 6$ million public funding. There was misfortune in timing, given the regulatory changes occurring at the time and some weaknesses in effectively overcoming practical hurdles might have been solved more readily if a committed CRO had been at the ready, budget permitting. But in more than one aspect, funding became a major factor and many interviewees in the BAMI study volunteered comparisons between the academic trial and the usual industry-sponsored trials their local teams contribute to.

The question then arises whether clinical teams are equipped to conduct such trials at all, whether therapy development for stage III trials should be left to industry alone. The autologous BMSC procedure trialed in BAMI may increase life expectancy and quality of life for patients after severe myocardial infarction, but there is no incentive for industry to engage with this option. Cell sources and therapy approaches that can be mass produced are more attractive and seen by many as the one indicator for successful RM, as confirmed again in a recent panel debate about regulation on RegMedNet [29]. That is why industry sponsorship for autologous SC studies is barely available. The consequence of excluding clinicians and their research projects from getting into the clinic if they don't pass the industry sponsorship and support threshold would mean that SC treatments, regardless of their efficacy, cannot reach the clinic, if the Scientific Innovation Model and the current regulatory set up remain the only acceptable way of establishing stem cell treatments. That, however, is difficult to justify, because effective treatment routes would be foreclosed before they have been tried out. In Europe, where many are doubtful about the safety and ethical acceptability of highly processed cell products in human medicine, this would be particularly indefensible, both ethically and politically.

It may be argued that the BAMI observations indicate that the current European framework does more than only restrict SC innovation to trials operating in the scientific modus (Model I). Even for RM research that operates firmly within this scientific innovation model, the regulations pose problems. Although a poster child in the parameters of scientific innovation, BAMI became almost undoable. This structural problem of European regulation demands rethinking the situation. Other routes to validating research designs that might be efficacious are needed. The methodological weaknesses of the CT have been discussed for decades, the other problems presented above show that new concepts of medical translation or innovation are needed for RM. Salter, Zhou and Datta $[4,5]$ argue that the current regulatory setup in Europe is primarily modeled on advancing RM as scientific innovation, giving the clinician the appetizer of the hospital exemption rule to contribute at the onset of trialing a new approach. Other parts of the world, favoring types of medical innovation over the scientific one, seem to have chosen more promising routes to bringing RM to the patients who need and demand it.

\section{Conclusion}

The role of academic medicine in the development of future treatments cannot be answered on the basis of this case study. But it should be apparent that the judgement of clinical practitioners is critical at every stage of medical innovation, be that an exemption situation in a first patient application or the assessment of the benefits of a new treatment to large patient populations beyond statistical significance. Therefore, it would seem sensible, given the many trials with autologous cell procedures that academics are keen to investigate, to include their perspective and approach when searching for commercially viable SC RM. This is underlined in Europe when considering the ethical point of view and recognizing the moral tensions over SC research. The high public and political investment that has been afforded this field, points to a political need for regulation that enables the trialing of the diverse therapeutic approaches that scientists and clinicians have reasons to pursue in the interest of best patient care.

From the case study, it is impossible to draw conclusions regarding whether academic teams can or cannot run Phase III trials. To take an informed view on this would require a much wider study including trials that are not affected by the triple set of regulations in which CT regulation and diverse hospital ethics are added to by strict regulation of the medical treatment as such. The third regulatory apparatus is specific for the field of cell therapies and one entry point at which the complex process of developing a suitable regulatory infrastructure that serves 
Box 1. Selected issues to consider for researchers embarking on a multinational stem cell trial.

- Discussion with the regulator in the preparatory stage might be useful, to be certain that you are familiar with the regulatory procedures that will be in force when the trial starts

- Access to licensed cell processing facilities must be arranged, affordable and staffed

- If cell or cell product transportation is necessary, consider all licensing and export permission needs

- Clinical practice on the ground varies in many little ways. Harmonized protocols require detailed alignment and extra capacity to adapt for National Competent Authority or local ethics approval requirements

- Cultural issues differ by location, state, country and traditions. Provisions must be available to cater for local needs so that they can be aligned to scientific and voluntary harmonization procedure protocols

- Time delays and the multiple ways in which they affect the cost of equipment, staff and cause more time delays and regulatory re-approvals should be avoided if at all possible

- A very big team that makes a timely concerted effort might be preferable but requires a firm management structure to govern a large consortium of partners with different roles

RM and patients might need more work. The non-negotiable binary classification between somatic cell therapy or ATMP probably needs more transparency in its application and refinement and openness for discussion given that clinician scientists advance new ways of using cells and tissues therapeutically. The current regulatory set-up must be refined and a wider consultation should be engaged in about the EUTCD classification of all nonhomologous autologous SC procedures as ATMP [30], as many clinicians, not only in BAMI, regard this as out of proportion and stifling for the development of affordable SC procedures.

A third conclusion that arises from the case study is that as long as academic teams engage in RM trials, they need support. The European Commission already recognized this when funding the AGORA project, that aimed to support Phase I and II ATMP CTs [31], but that project is completed and there is no permanent institution available that supports new or Phase III trials. Given that all multinational RM trials in Europe by clinical teams will face many of the problems described above, the solution of a private professional CRO is one option, but it is expensive and does not create a publicly accountable and accessible location for the expertise that is bought in. An initially not cheaper, but publicly shared and more transparent solution would be to create one or several CRO expertise hubs that would offer clinicians who run autologous RM trials on inevitably tight budgets to draw on this knowledge. Autologous and allogenic SC therapy development may require different forms of oversight and support, given that the major sponsors of CTs do not equally favor them. A European-wide institution, possibly at the EMA, that supports academic trials seems necessary to attain this goal of SC RM innovation in Europe on a broad platform. For trials with scientific merit, assured in BAMI's case by the literature and confirmed by the peer review process in the context of the funding application, the CRO infrastructure of support should be provided by the regulator.

Another potentially substantial advantage from such a public expertise hub would be that the knowledge about differences in healthcare systems, insurance provisions, information needs, translation issues, the contracts GMP laboratories offer and so forth to become public property and accumulate in the European public sphere. That would save a lot of future work and time and might also help to better understand how the remits of different sets of regulations intersect with national institutional contexts and thus help better policy making in the health sector. The interest of the regulators needs to be in tune with the interests of patients and healthcare providers. Otherwise the scientific innovation pathway in Europe will be designed to exclude academic research based on medical experience that carries low risks but potentially high benefits.

On a more practical note, as long as the surrounding conditions persist, the case study might help other teams of clinician scientists to approach their trials with more preparation. For academic researchers embarking on a multinational SC trial, Box 1 provides a brief summary of issues to consider that might prove useful.

\footnotetext{
Acknowledgements

The consistent and generous cooperation of the BAMI team, especially the support of the trial coordinator A Mathur at Queen Mary University, London, and S Dowlut at the BAMI trial office are gratefully acknowledged. I also thank J Harrington and N Baur for their assistance with the empirical data collection.
} 
Summary points

- This report on the problems encountered during an academic European stem cell (SC) trial could be helpful to clinicians setting out on similar enterprises.

- Clinician-scientists' pursuit of research based on their medical experience can be stifled by the current regulatory regime in packed in Europe.

- Multiple regulations covering SC use are simultaneously effective in containing marketing of unproven treatments but also the clinical translation of autologous SC treatments, which is hampered additionally by lack of industry sponsorship.

- One might state ethical contradictions between the public support, morally and financially, for SC research and the limiting effects of regulation on particular directions of this research that should be addressed by regulators, in cooperation with scientists and publics.

- One effective intervention to overcome the structural disadvantage of academic research and autologous SC translation could be a free Clinical Research Organization hub for such research at the EMA.

- The findings support the questioning of scientific innovation by clinical trial and the debate about new pathways for safe, efficacious and valid SC regenerative medicine.

Financial \& competing interests disclosure

This research was funded by the European Commission under the Seventh Framework program, HEALTH (Grant agreement number 278967). The author has no other relevant affiliation or financial involvement with any organization or entity with a financial interest in or financial conflict with the subject matter or materials discussed in the manuscript apart from those disclosed.

No writing assistance was utilized in the production of this manuscript.

Ethical conduct of research

The authors state that they have obtained appropriate institutional review board approval or have followed the principles outlined in the Declaration of Helsinki for all human or animal experimental investigations. In addition, for investigations involving human subjects, informed consent has been obtained from the participants involved.

\section{Open access}

This work is licensed under the Attribution-NonCommercial-NoDerivatives 4.0 Unported License. To view a copy of this license, visit http://creativecommons.org/licenses/by-nc-nd/4.0/

\section{References}

1. Wainwright SP, Williams C, Michael M, Farsides B, Cribb A. From bench to bedside? biomedical scientists' expectations of stem cell science as a future therapy for diabetes. Soc. Sci. Med. 63(8), 2052-2064 (2006).

2. Woolf SH. The meaning of translational research and why it matters. JAMA 299(2), 211-213 (2008).

3. Harrington J, Hauskeller C. Translational research: an imperative shaping the spaces in biomedicine. TECNOSCIENZA 5(1), 191-201 (2011).

4. Salter B, Zhou Y, Datta S. Health consumers and stem cell therapy innovation: markets, models and regulation. Regen. Med. 9(3), 353-366 (2014).

5. Salter B, Zhou Y, Datta S. Hegemony in the marketplace of biomedical innovation: consumer demand and stem cell science. Soc. Sci. Med. 131, 156-163 (2015).

6. Petersen A, Munsie M, Tanner C, Macgregor C, Brophy J. Health Technology and Society. In: Stem Cell Tourism and the Political Economy of Hope. Palgrave MacMillan, London, UK (2017).

7. Patra PK, Sleeboom-Faulkner M. Recruiter-patients as ambiguous symbols of health: bionetworking and stem cell therapy in India. New Genet. Soc. 30(2), 155-166 (2011).

8. Taylor PL, Barker RA, Blume KG et al. Patients beware: commercialized stem cell treatments on the web. Cell Stem Cell 7(1), 43-49 (2010).

9. Ryan KA, Sanders AN, Wang DD, Levine AD. Tracking the rise of stem cell tourism. Regen. Med. 5(1), 27-33 (2010).

10. Bhardawaj A. Ethic of consensibility, subaltern ethicality: the clinical application of embryonic stem cells in India. BioSocieties 8, 25-40 (2013).

11. Sipp D. The unregulated commercialization of stem cell treatments: a global perspective. Front. Med. 5(4), 348-355 (2011).

12. Berger I, Ahmad A, Bansal A et al. Distribution of businesses marketing stem-cell based interventions. Cell Stem Cell 19(2), 158-162 (2016). 
13. Daley GQ, Hyun I, Apperley JF et al. Setting global standards for stem cell research and clinical translation: the 2016 ISSCR Guidelines. ISSCR Stem Cell Rep. 6(j), 787-797 (2016).

14. ISSCR (2016). Guidelines for stem cell research and clinical translation. http://www.isscr.org/home/publications/2016-guidelines

15. Hauskeller C. Direct to consumer genetic testing: regulations cannot guarantee responsible use; an international industry certificate is needed. BMJ 342, d2317 (2011).

16. Turner L, Knoepfler P. Selling stem cells in the USA: assessing the direct-to-consumer industry. Cell Stem Cell 19(2), 154-157 (2016).

17. Stacey G, Stephens N. Social science in a stem cell laboratory: what happened when social and life sciences met. Regen. Med. 7(1), 117-126 (2012).

18. Bender W, Manzei A, Hauskeller C. Crossing Borders. Ethical, Legal, Economic and Religious Views on Stem Cell Research. Global Perspectives, Münster, Agenda Verlag, Germany (2006).

19. Wilson D. Creating the 'ethics industry': Mary Warnock, in vitro fertilization and the history of bioethics in Britain. BioSocieties 6(2), 121-141 (2011).

20. Hauskeller C. Science in touch. Functions of biomedical terminology. Biol. Philos. 20(4), 815-835 (2005).

21. Hauskeller C. How traditions of ethical reasoning and institutional processes shape stem cell research in the UK. J. Med. Philos. 29(5), 509-532 (2004).

22. Martin P, Brown N, Kraft A. From bedside to bench? Communities of promise, translational research and the making of blood stem cells. Sci. Cult. 17(1), 29-41 (2008).

23. Goldthwaite CA. Mending broken hearts. Stem cells and cardia repair (2006). https://stemcells.nih.gov/info/Regenerative_Medicine/2006Chapter6.htm

24. Mozid AM, Samer A, Sammut EC, Mathur A. Stem cell therapy for heart diseases. Br. Med. Bull. 98(1), 143-159 (2011).

25. Mathur A, Fernandez-Aviles F, Dimmeler S et al. Consensus of the task force of the European Society of Cardiology concerning the clinical investigation of the use of autologous adult stem cells for repair of the heart - update 2016. Eur. Heart J. doi:10.1093/eurheartj/ehw640 (2017) (Epub ahead of print).

26. Hauskeller C, Baur N. Travelling cells - harmonized European regulation and the BAMI Stem Cell Trial. In: Stem Cells in Clinical Translation: Science: Safety, Ethics and Regulations. Pham P, Rosemann A (Eds). Springer, Singapore (2017) (In press).

27. Hauskeller C, Baur N, Harrington J. Standards, harmonization and cultural differences: examining the implementation of a European Stem Cell Clinical Trial. Sci. Cult. (2017). http://dx.doi.org/10.1080/09505431.2017.1347613

28. Stephens N, Lewis J, Atkinson P. Closing the regulatory regress: GMP accreditation in stem cell laboratories. Sociol. Health Illn. 35(3), 345-360 (2013).

29. RegMedNet - panel discussion on cell therapy regulation (2017). www.regmednet.com/users/3641-regmednet/posts/16997-panel-discussion-on-cell-therapy-regulation

30. Weber S, Wilson-Kovacs D, Hauskeller C. The regulation of stem cell therapies: comparing the UK and Germany. Human Tissue Research. Lenk C, Hoppe N, Beier K, Wiesemann C (Eds). Oxford University Press, Oxford, UK, 159-167 (2010).

31. Final Report Summary AGORA. http://cordis.europa.eu/result/rcn/177747_en.html 